\title{
EFFECT OF OXYTOCIN ADMINISTRATION ON THE OESTROUS CYCLE OF UNILATERALLY HYSTERECTOMIZED HEIFERS
}

\author{
O. J. GINTHER, G. O. WOODY, S. MAHAJAN, \\ K. JANAKIRAMAN AND L. E. CASIDA \\ Genetics Laboratory, University of Wisconsin, \\ Madison, Wisconsin, U.S.A.
}

(Received 14th Fune 1966)

\begin{abstract}
Summary. The effect of oxytocin administration on the oestrous cycle was studied in sixteen uterine-intact and thirty-two surgically prepared unicornual heifers. Unilateral hysterectomy was performed on Day 3 of the oestrous cycle and oxytocin or an equivalent volume of physiological saline was administered daily from Day 3 to Day 7 or 8. Oxytocin produced significantly shorter oestrous cycles in the intact heifers and in the unicornual heifers with the retained uterine horn adjacent to the GL, but not in the unicornual heifers with the retained horn opposite to the CL. These results strongly suggest that at least part of the effect of oxytocin is exerted through local, utero-ovarian channels. A unilateral effect of the uterus on the GL was demonstrated in unicornual heifers that did not receive oxytocin. The oestrous cycles were extended and the CL persisted when the retained horn was opposite to the CL, but not when the retained horn was adjacent to the CL.
\end{abstract}

\section{INTRODUCTION}

Oxytocin administered to cattle during the first week after oestrus results in shortened oestrous cycles. However, exogenous oxytocin does not produce precocious oestrus in hysterectomized cattle (Armstrong \& Hansel, 1959). A local or unilateral influence of the uterus on the corpus luteum has been demonstrated by means of: (1) unilateral pregnancy in swine (du Buisson, 1961a), (2) partial or unilateral hysterectomy in guinea-pigs (Fischer, 1965), pseudopregnant rats (Anderson, Melampy \& Chen, 1966), sheep (Moor \& Rowson, 1966) and swine (du Buisson, 1961b), and (3) unilateral uterine distension in cattle (Ginther, Woody, Janakiraman \& Casida, 1966), guineapigs (Bland \& Donovan, 1965) and sheep (Ginther, Pope \& Casida, 1965).

Because of the evidence that the uterus may be involved in the precocious oestrus following the injection of exogenous oxytocin and because of the recent evidence of a local influence of the uterus on the corpus luteum, an experiment was designed to test the hypothesis that the precocious oestrus following oxytocin administration in cattle occurs through local, utero-ovarian mechanisms. 
It was postulated that oxytocin would produce precocious oestrus in unilaterally hysterectomized heifers if the retained uterine horn was adjacent to the ovary containing the corpus luteum (CL), but not if the retained horn was opposite to the $\mathrm{Cr}$.

\section{MATERIALS AND METHODS}

The experiment was conducted from December 1965 to May 1966, and involved forty-eight Holstein heifers weighing 300 to $400 \mathrm{~kg}$. The heifers were observed twice daily for oestrus before and throughout the experimental period. Only heifers that exhibited one or two cycles 17.5 to 23.5 days in length, immediately before treatment, were used. The forty-eight heifers were assigned to treatment groups by complete randomization within three replicates of twenty-four, twelve and twelve heifers. Six treatment groups were used: (1) intact uterus, saline injected; (2) intact uterus, oxytocin injected; (3) unilaterally hysterectomized with the retained uterine horn adjacent to CL, saline injected; (4) retained uterine horn adjacent to CL, oxytocin injected; (5) retained uterine horn opposite to $\mathrm{CL}$, saline injected; and (6) retained uterine horn opposite to $\mathrm{CL}$, oxytocin injected.

Oxytocin-injected heifers were given a daily dose of 100 USP units of purified oxytocin principle, subcutaneously, from Day 3 to Day 7, except for those of the third replicate, which were given a daily dose of 150 units from Day 3 to Day 8 (oestrus = Day 1). Saline-injected heifers were given an equivalent volume of physiological saline under the same treatment regimen.

Unilateral hysterectomy was performed under general anaesthesia on Day 3 of the oestrous cycle. The heifers were isolated from feed and water for 36 to $48 \mathrm{hr}$ before surgery. Anaesthesia was begun with the heifer in the standing position by the intravenous administration of a preparation containing chloralhydrate, magnesium sulphate and sodium pentobarbital (Equi-thesin, JensenSalsbery Laboratories, Kansas City, Missouri). The anaesthetic was administered as rapidly as it would gravitate through a 16 gauge needle from a height of approximately $1 \mathrm{~m}$. After the heifer went down, administration was continued more slowly until light surgical anaesthesia was reached. A longitudinal skin incision and a transverse tracheotomy were made on the ventral midline of the neck and a Dyson tracheal tube (Jensen-Salsbery Laboratories) was inserted between two tracheal cartilages. The anaesthetized heifer was secured in dorsal recumbency with caudal elevation in a surgical cradle similar to that described by Neal \& Nelson (1962).

The uterus and ovaries were exposed by means of a midventral laparotomy aided by a Balfour abdominal retractor (Arista Surgical Co., New York). A 20- to 23-cm incision was made through the skin and abdominal wall extending forward from a point between the caudal two mammary glands. The reproductive tract was retracted by means of two lengths of wide umbilical tape which were tied to the uterine horn that was to be removed. The caudal uterine vessels on the side of unilateral hysterectomy were ligated near the cervix with heavy Vetafil suture (Norden Laboratories, Lincoln, Nebraska, U.S.A.). The oviduct and associated vessels were ligated about $2 \mathrm{~cm}$ above the tubo-uterine junction. The extensive network of blood vessels at the cranial 
half of the uterine horn were ligated en masse by means of a row of five to six overlapping ligatures. These ligatures and the incision through the broad ligament were made close to the mesometrial-uterine junction to avoid interference with the ovarian blood supply. Ligatures were also placed in the intercornual area whenever necessary to control haemorrhage. The entire uterine horn and the adjacent, lateral half of the uterine body were freed, a ligature placed near the cervix and the uterine tissue excised. The opening into the retained half of the uterine body was not closed. Throughout the operation the reproductive tract was kept moist with physiological saline. The newlyforming CL was marked with India ink. The tracheal tube was removed at the end of the operation and the tracheal incision was closed with two sutures in the fascial layer of the ventral neck muscles.

Following recovery from anaesthesia the surgically prepared unicornual heifers, as well as the non-operated, uterine-intact heifers, were palpated per rectum periodically and observed twice daily for oestrus. Heifers that did not show well-defined oestrus were slaughtered on Day 26. At slaughter, the appearance and weight of the marked CL were recorded and both ovaries were checked for new cL to determine if unobserved oestrus had occurred.

\section{RESULTS AND DISCUSSION}

The method of anaesthesia and surgery permitted excellent exposure of the reproductive tract. Four cases of severe and a few cases of mild regurgitation of rumen contents occurred during the thirty-two operations. However, the tracheal tube assured a patent airway even in the most severe cases of regurgitation. Rectal palpation indicated that the reproductive tract remained reasonably free of adhesions. In twenty-six of the thirty-two unilaterally hysterectomized heifers, both ovaries and the retained horn were freely palpable.

Of the sixteen uterine-intact heifers, the eight that received saline had an average oestrous cycle length of 20.3 days compared to 12.9 days for the eight that received oxytocin. Of the sixteen unicornual heifers with the retained horn adjacent to the $\mathrm{CL}$, the eight that received saline had an average cycle length of $21 \cdot 1$ days compared with 16.2 days for the eight that received oxytocin (Table 1). The oestrous cycle lengths of these four groups were analysed by an analysis of variance for a $2 \times 2$ factorial experiment (Steel \& Torrie, 1960). The oestrous cycles were shorter for the oxytocin-injected than for the salineinjected heifers $(P<0 \cdot 01)$. However, there was no significant difference in cycle length between the uterine-intact heifers and the unicornual heifers with the retained horn adjacent to the CL. There was no interaction between the two types of treatments, oxytocin versus saline and uterine-intact versus unicornual (Table 1).

Of the sixteen unicornual heifers with the retained uterine horn opposite to the CL, seven of eight that received saline did not return to oestrus before slaughter at Day 26 and the remaining heifer had a 22.5-day cycle; similarly, seven of eight that received oxytocin did not return to oestrus and the remaining heifer had a 24-0-day cycle. Since fourteen of the sixteen heifers in these two groups were killed before they returned to oestrus, the average oestrous cycle length, 
although definitely prolonged, could not be estimated and the data were not analysed further. Unobserved oestrus did not occur in the fourteen slaughtered heifers as evidenced by the lack of newly-forming CL at autopsy.

The above results show that oxytocin produced precocious oestrus in uterineintact heifers and in unicornual heifers with the retained horn adjacent to the CL, but not in unicornual heifers with the retained horn opposite to the CL. There was no significant difference between the length of the cycles of the oxytocin-treated, uterine-intact heifers and those of the oxytocin-treated, unicornual heifers with the retained horn adjacent to the GL (no interaction, Table 1). These results strongly suggest that at least part of the action of exogenous oxytocin in cattle is through local, utero-ovarian channels.

The ink-marked, Day-26 cL of the fourteen slaughtered, unicornual heifers with the retained horn opposite to the CL, were non-cystic and were normal in gross appearance. However, the weight of the Day-26 cL from the seven

\section{TABLE 1}

OESTROUS GYCLE LENGTHS OF UTERINE-INTACT AND SURGIGALLY PREPARED UNICORNUAL HEIFERS THAT RECEIVED OXYTOGIN OR SALINE INJEGTIONS

\begin{tabular}{l|c|c|c|c|c|c}
\hline \multirow{2}{*}{ Item } & \multicolumn{2}{|c|}{$\begin{array}{c}\text { Uterine-intact } \\
\text { heifers }\end{array}$} & \multicolumn{3}{|c}{ Unilaterally hysterectomized heifers } \\
\cline { 2 - 6 } & $\begin{array}{c}\text { Retained horn adjacent } \\
\text { to corpus luteum }\end{array}$ & $\begin{array}{c}\text { Retained horn opposite } \\
\text { to corpus luteum }\end{array}$ \\
\cline { 2 - 6 } & $\begin{array}{c}\text { Saline } \\
\text { injected }\end{array}$ & $\begin{array}{c}\text { Oxytocin } \\
\text { injected }\end{array}$ & $\begin{array}{c}\text { Saline } \\
\text { injected }\end{array}$ & $\begin{array}{c}\text { Oxytocin } \\
\text { injected }\end{array}$ & $\begin{array}{c}\text { Saline } \\
\text { injected }\end{array}$ & $\begin{array}{c}\text { Oxytocin } \\
\text { injected }\end{array}$ \\
\hline $\begin{array}{l}\text { No. heifers } \\
\begin{array}{c}\text { Average oestrous cycle } \\
\text { length* (days) }\end{array}\end{array}$ & 8 & 8 & 8 & 8 & 8 \\
\hline
\end{tabular}

* Mean squares from analysis of variance of first four groups: saline-injected versus oxytocininjected, $303(P<0.01)$; uterine-intact versus retained horn adjacent to cL, 33; interaction, 13; error, 12 .

$\uparrow$ The cycle lengths of seven of the eight heifers were greater than 25 days and the remaining heifer had a 22.5-day cycle.

$\$$ The cycle lengths of seven of the eight heifers were greater than 25 days and the remaining heifer had a 24-0-day cycle.

slaughtered heifers that received oxytocin (average $3 \cdot 42$; range, $2 \cdot 38$ to $4 \cdot 17 \mathrm{~g}$ ) was less $(P<0.05)$ than for the seven that received saline (average 4.34 ; range, 3.20 to $5.60 \mathrm{~g}$ ). These results suggest that there may have been some effect of oxytocin on the CL in the heifers with the retained horn opposite to the CL, even though precocious oestrus did not occur. It should be noted, however, that this calculation does not include the weight of the Day-26 CL of the salineinjected heifer that returned to oestrus at 22.5 days and the oxytocin-injected heifer that returned to oestrus at $24 \cdot 0$ days.

A unilateral effect of the uterus on the cL was demonstrated in the sixteen surgically prepared unicornual heifers that did not receive oxytocin. The oestrous cycles were extended and the cL persisted when the retained horn was opposite to the $\mathrm{CL}$, but not when the retained horn was adjacent to the CL. To obtain information on the duration of CL persistence beyond Day 26, subsequent cycles were studied in six of the unicornual heifers following the post-treatment oestrus. 
The side of ovulation was determined by rectal palpation and the heifers were, thereafter, palpated at weekly intervals. Four subsequent cycles in which the retained horn was adjacent to the CL were 18.5, 19.0, 22.5 and 23.5 days in length. Six subsequent cycles in which the retained horn was opposite to the CL were $27 \cdot 0,81 \cdot 5,>114,>122,>128$ and $>150$ days. These results in cattle are consistent with the results of previous reports of unilateral or partial hysterectomy in guinea-pigs, pseudopregnant rats, sheep and swine.

\section{ACKNOWLEDGMENTS}

Paper No. 1085 from the Genetics Laboratory, published with the approval of the Director of the Agricultural Experiment Station. This study was done under a cooperative agreement between the Wisconsin Agricultural Experiment Station and the Dairy Cattle Research Branch, U.S.D.A. The work was supported in part by the Branch and also by a grant from the Ford Foundation. One of us (O.J.G.) was supported by a United States Public Health Service post-doctoral fellowship, No. 1 F2 HD-23, 054-01, from the National Institute of Child Health and Human Development.

\section{REFERENCES}

Anderson, L. L., Melampy, R. M. \& Chen, C. L. (1966) The uterus and ovarian activity in the pseudopregnant rat. Anat. Rec. 154, 306. (Abstr.).

Armstrong, D. T. \& Hansed, W. (1959) Alteration of the bovine estrous cycle with oxytocin. F. Dairy Sci. 42, 533.

BLANd, K. P. \& Donovan, B. T. (1965) Local control of luteal function by the uterus of the guinea-pig. Nature, Lond. 207, 867.

Du Bursson, F. Du M. (1961a) Possibilité d'un fonctionnement dissemblable des ovaries pendant la gestation chez la truie. C.r. hebd. Séanc. Acad. Sci., Paris, 253, 727.

Du Bursson, F. Du M. (1961b) Régression unilatérale des corps jaunes aprés hystérectomie partielle chez la truie. Annals Biol. anim. Biochim. Biophys. 1, 105.

Fischer, T. V. (1965) Local uterine inhibition of the corpus luteum in the guinea-pig. Anat. Rec. 151, 350. (Abstr.).

Ginther, O. J., Pope, A. L. \& Casida, L. E. (1965) Some effects of intra-uterine plastic coils in ewes. 7. Anim. Sci. 24, 918. (Abstr.).

Ginther, O. J., Woody, G. O., Janakiraman, K. \& Casida, L. E. (1966) Effect of an intra-uterine plastic coil on the oestrous cycle of the heifer. F. Reprod. Fert. 12, 193.

Moor, R. M. \& Rowson, L. E. A. (1966) Local uterine mechanisms affecting luteal function in the sheep. F. Reprod. Fert. 11, 307.

Neal, F. C. \& Nelson, H. A. (1962) Use of a surgical cradle and incision retractor for cattle. F. Am. vet. med. Ass. 141, 459.

Steel, R. G. D. \& TORRIE, J. H. (1960) Principles and procedures of statistics. McGraw-Hill, New York. 